\title{
A miniaturized thin-plate low cycle fatigue test method at elevated temperature
}

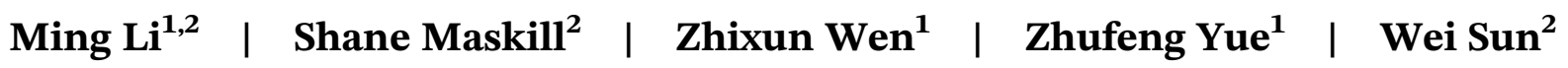

\author{
${ }^{1}$ School of Mechanics, Civil Engineering \\ and Architecture, Northwestern \\ Polytechnical University, Xi'an, China \\ ${ }^{2}$ Faculty of Engineering, University of \\ Nottingham, Nottingham, UK

\section{Correspondence} \\ Ming Li, School of Mechanics, Civil \\ Engineering and Architecture, \\ Northwestern Polytechnical University, \\ Xi'an 710072, China. \\ Email: ming.li1@nwpu.edu.cn

\section{Funding information} \\ Engineering and Physical Sciences \\ Research Council, Grant/Award Number: \\ EP/N509991/1; National Natural Science \\ Foundation of China, Grant/Award \\ Number: 51875461
}

\begin{abstract}
This study aims to develop a high-temperature low cycle fatigue test method using a nonstandard miniature thin-plate specimen in order to characterize the cyclic viscoplasticity behavior of a component material. For demonstration, fully reversed strain-range controlled low cycle fatigue and creep-fatigue tests at $600^{\circ} \mathrm{C}$ have been performed for a martensitic steel using standard-sized fullscale specimens and miniaturized thin-plate specimens, respectively. Because the displacement is not directly measured from the uniform gauge section of the miniaturized specimen, a geometry-dependent scaling factor is obtained and used to convert the uniaxial strain. The results obtained are shown that the miniaturized test method developed in this work has exhibited a clear possibility to produce comparable low cycle fatigue data with those that are normally obtained by conventional standard specimen tests.
\end{abstract}

\section{K E Y W O R D S}

low cycle fatigue, miniature thin-plate, scaling factor, unified viscoplasticity model

\section{1 | INTRODUCTION}

High-temperature thermal components such as gas turbine rotor, ${ }^{1}$ fossil fuel plant pressurized vessel,,${ }^{2,3}$ and aeroengine combustion structure ${ }^{4}$ may fail due to the long-term accumulated damage caused by creep, fatigue, and creep-fatigue (CF) interaction at elevated temperature. In industrial application, it is inevitably required to evaluate the material properties and residual life of such in-service components, which has led to the development of nondestructive or "quasi" nondestructive techniques. ${ }^{5}$ Based on these demands, various small-sized testing techniques have been developed ${ }^{6-9}$ and are being increasingly used to assist in condition minoring and life management programs. ${ }^{10-12}$ However, in order to obtain the equivalent or close mechanical behavior to the standard-sized fullscale (SSFS) test, there are three critical issues on the development of miniaturized testing: (i) standardization of high-temperature low cycle fatigue (LCF) miniature specimen for sub-sized thin structures, for example, coating-substrate systems ${ }^{13,14}$ or narrow heat-affected zones (HAZs), ${ }^{2,15}$ (ii) improvement in LCF testing apparatus leading to high-accuracy test rig, and (iii) robust mechanics-based theoretical method for fatigue data correlation.

Data from small specimen creep test have a direct input into the remaining life evaluation and become increasingly attractive for power plant application. ${ }^{16}$ Such data can also be used to generate constitutive laws for the welded material. ${ }^{17,18}$ The main small-sized specimen and testing types that are used to obtain high-temperature creep properties including the conventional sub-sized uniaxial specimens ${ }^{19}$ and several miniaturized types, including impression creep test, ${ }^{20-22}$ small punch tensile, 
creep and fracture tests, ${ }^{23-27}$ small ring creep test, ${ }^{28-30}$ small tensile two-bar creep test ${ }^{31}$ and the more recent miniature thin-plate (MTP) tensile test. ${ }^{32}$ One of the unique advantages that small punch creep test has is the very small thickness $(\sim 0.5 \mathrm{~mm})$; however, there is no universally accepted conversion technique available for data interpretation. ${ }^{33,34}$ Recently, small punch-related constitutive model was developed to predict the uniaxial stress-strain response based on the energy dissipation principle, which was capable to convert the loaddisplacement data into stress-strain description. ${ }^{35}$ In addition, instrumented indentation test (IIT) was applied in remaining life assessment, and the numerical results were compared with the experimental data of the standard specimen. ${ }^{36}$ Impression creep test requires a small amount of material to only produce steady-state creep data after a transient primary stage, which is attractive in characterizing the localized deformation and damage behavior. ${ }^{37,38}$ The two-bar specimen can produce the fullstage creep curve, but it is difficult to make it very thin to ensure that the two bars fail at the same time. The inverse approaches ${ }^{39,40}$ have been adopted in miniaturized testing to obtain creep properties based on the analytical solutions and numerical modeling.

Up to date, most of the research focuses on the miniaturized creep test; however, there has been a significant missing gap in the miniaturized LCF test at elevated temperature as many issues are still waiting for the technical solutions. ${ }^{41-43}$ For example, almost all the testing apparatuses, such as the testing rigs and gripping fixtures, are specially designed for standard specimens. Moreover, the miniature specimen is apt to suffer from torsional damage during high-temperature fatigue test. In the recent years, the cylindrical small-sized specimen had been successfully applied for LCF test by Dzugan et $\mathrm{al}^{42,43}$; however, the test results were not compared with the standard fatigue test. The small punch high cycle fatigue test had been conducted for Ti- $6 \mathrm{Al}-4 \mathrm{~V}^{44,45}$; however, it was very difficult to derive the stress-strain hysteresis response. An alternative miniature fatigue test method, using a thin-plate specimen, could provide much more reliable data. For example, LCF test was carried out by Nozaki et al, ${ }^{46}$ and Nogami et $a l,{ }^{47}$ using round bar and thin-plate specimens, and little difference was found in fatigue response. Thermal-mechanical fatigue tests were carried out in Ni-based superalloy, and the results showed a comparable response in fatigue life between the miniaturized and standardized specimens. ${ }^{48}$ Although the miniature LCF test mentioned above has paved the way for representing the cyclic plasticity behavior of the SSFS fatigue test using a relatively long gauge length, ${ }^{46-48}$ more extensive investigations into the LCF and CF with smaller-sized specimens at higher temperature are still needed before standardization of the miniaturized test.

The current work proposes a new experimental and numerical framework, which aims to duplicate the LCF behavior of the SSFS specimen by using a nonstandard MTP specimen at elevated temperature. The organization of the paper is as follows: The experimental methodology is presented in Section 2, consisting of material, specimen design, experimental setup, and a comparison of uniaxial response between the SSFS and MTP tests. A hightemperature unified viscoplasticity (UVP) modeling is introduced in Section 3 including data interpretation. The comparison of high-temperature LCF results between MTP and SSFS tests is given in Section 4, followed by detailed conclusions and discussion in Section 5 .

\section{2 | EXPERIMENTAL METHODOLOGY}

\section{1 | Material and test program}

The material used in this research is a martensitic FV566 steel extracted from an area close to the centerline of a gas turbine rotor, where it was service-aged for approximately $90,000 \mathrm{~h}$ at $\sim 420^{\circ} \mathrm{C}$ and maximum speed of $3000 \mathrm{rpm}$. The chemical composition of the material includes (wt.\%): C, 0.6; Si, 0.038; Mn, 0.668; $\mathrm{Cr}, 11.9$; Mo, 1.68; Ni, 2.52; V, 0.298; S, 0.006; and Fe, remainder.

Uniaxial tensile, fully reversed sawtooth, and holddwell LCF tests at a strain rate of $0.01 \% \mathrm{~s}^{-1}$ until failure had been carried out for the SSFS specimen previously. ${ }^{1}$ The geometry and dimensions of the SSFS specimen used in this work are given in Figure 1A. All the straincontrolled LCF and CF tests were conducted at $600^{\circ} \mathrm{C}$ under a total strain range of $\pm 0.7 \%$ using two prescribed loading conditions, that is, sawtooth (Figure 1B) and dwell-type (Figure 1C) waveforms. A symmetrical triangular waveform (push-pull load ratio, $R_{e}=-1$ ) was employed for the sawtooth loading and a trapezoidal waveform for the dwell-type loading. For dwell-type test, the dwell period duration was imposed at the maximum tensile strain for a period of $150 \mathrm{~min}$ for the first cycle and $5 \mathrm{~min}$ for every subsequent cycle. The dwell duration was chosen after careful investigation of the stress relaxation (i.e., the 5-min hold period was enough to reach the quasi-equilibrium state of the viscous stress). The hightemperature LCF and CF tests for the SSFS specimen were performed on the Tinius Olsen H25KS electromechanical testing machine. More information can be found in the author's previous work. ${ }^{1,3}$ 


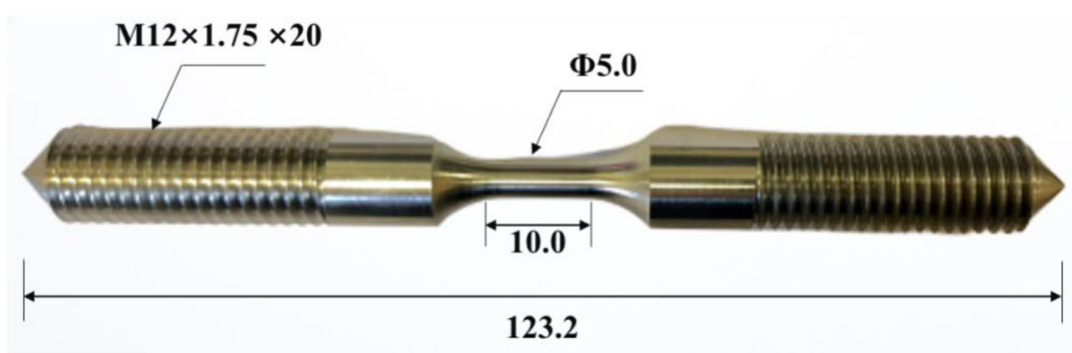

(A)

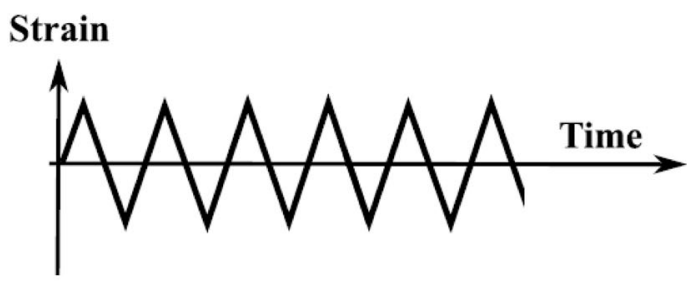

(B)

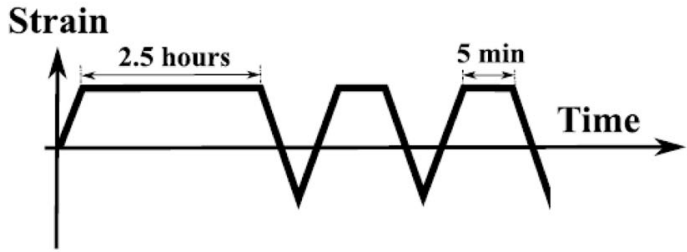

(C)

F I G U RE 1 (A) Geometry and dimensions of the SSFS round bar specimen used for uniaxial tensile, high-temperature LCF and CF tests (all measures given in $\mathrm{mm}$ ). (B) LCF sawtooth profile. (C) CF dwell-type profile for a hold period of 150 min for the initial cycle and 5 min hold period for every subsequent cycle [Colour figure can be viewed at wileyonlinelibrary.com]

\section{2 | Nonstandard MTP specimen design, test rig, and experimental setup}

Figure $2 \mathrm{~A}$ shows the geometry and dimensions of the nonstandard MTP specimen for high-temperature LCF and $\mathrm{CF}$ tests. The parallel gauge lengths, that is for example, $l_{0}=1.0 \mathrm{~mm}$ (MTP-1), $l_{0}=1.5 \mathrm{~mm}$ (MTP-2), and $l_{0}=2.0 \mathrm{~mm}$ (MTP-3), were chosen, as illustrated in Figure 2A. The remaining dimensions are given in Figure $2 \mathrm{~A}$ as well, with the thickness of $0.5 \mathrm{~mm}$, gauge width of $1.0 \mathrm{~mm}$, total width of $3.0 \mathrm{~mm}$, and fillet radius of $2.0 \mathrm{~mm}$. Note that the displacement can only be measured at the ends of the fillets because it is difficult to accommodate the extensometer into the very limited region, as illustrated in Figure 2A. Based on the previous findings,${ }^{49-51}$ the number of grains in the thickness direction should be at least five to six grains in order to minimize the size effect. According to the measured prior austenite grain size in our previous work, ${ }^{1,52}$ there are approximate 10 grains in the thickness direction of the MTP specimen. All the MTP specimens are given in Figure $2 \mathrm{~B}$, followed by the loading assembly and experimental setup in Figure 2C. Before the test, the mechanical scratches were removed from the MTP specimen by using the emery paper of \#1200 in order to minimize the deleterious effect on the fatigue behavior. The polished MTP specimen is clamped at both ends by specially designed and manufactured clamps with machined rough surfaces to strengthen the grip and reduce the slippage (see Figure 2D). The displacement is measured by two linear variable displacement transducers (LVDT) connected to both sides of the loading part.

\subsection{Uniaxial tensile test of MTP and SSFS specimens}

Prior to high-temperature LCF test, uniaxial tensile test had been performed on MTP-3 and compared with the SSFS test at 20 and $600^{\circ} \mathrm{C}$, respectively, in order to demonstrate the capability of the testing technique. The miniature uniaxial tensile test was performed on the testing rig as introduced in Figure 2C. The applied strain rate for MTP-3 specimen was $0.01 \% \mathrm{~s}^{-1}$ and consistent with the SSFS tensile test. ${ }^{1}$ The torque applied to both screw bolts were kept the same with a value of $0.5 \mathrm{Nm}$ to avoid any torsion and provide enough clamping force. As can be seen from the engineering stress-strain curves estimated from the initial cross-sectional area and displacement shown in Figure 3, the tensile responses from MTP-3 specimen follow typical temperature-dependent mechanical behaviors, for example, higher ultimate tensile response and lower ductility at $20^{\circ} \mathrm{C}$ compared with these at $600^{\circ} \mathrm{C}$. More importantly, the tensile tests carried out at 20 and $600^{\circ} \mathrm{C}$ using MTP-3 specimen are capable to approximately capture the overall behavior of the SSFS uniaxial tensile tests under the equivalent loading conditions. 


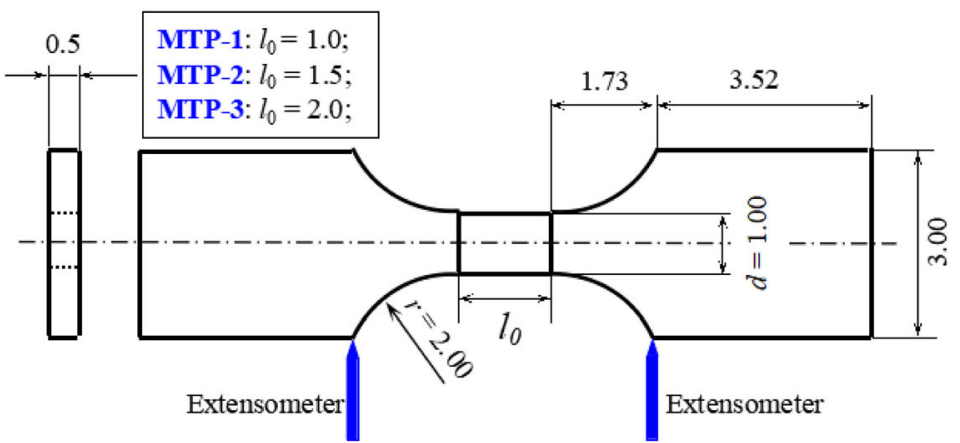

(A)

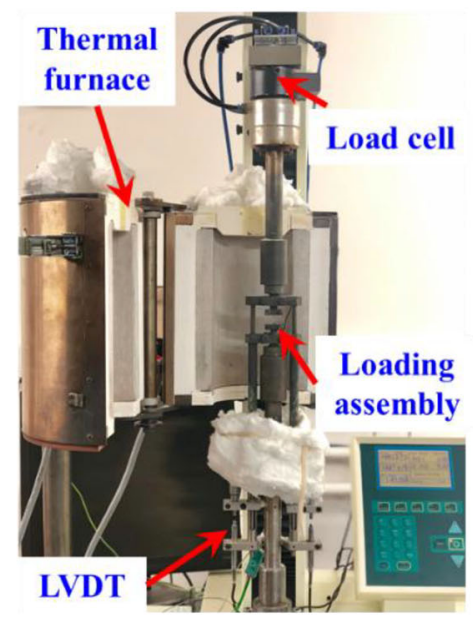

(C)

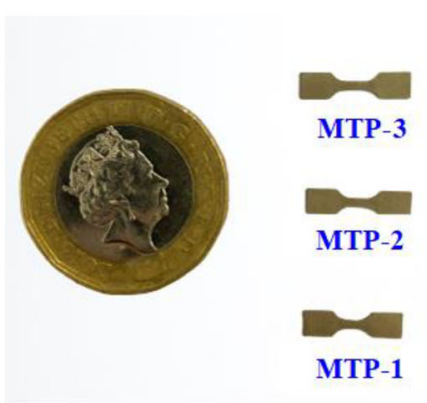

(B)

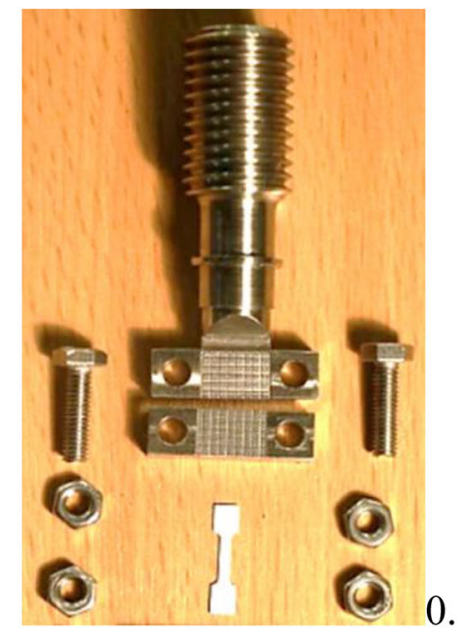

(D)

F I G U RE 2 (A) Geometry and dimensions of the MTP specimen for high-temperature tensile LCF and CF tests. (B) Three proposed MTP specimens with different parallel gauge lengths: $l_{0}=1.0$ (MTP-1), $l_{0}=1.5$ (MTP-2), and $l_{0}=2.0$ (MTP-3) (all measures given in mm). (C) The Tinius Olsen H25KS single-column high-temperature testing machine. (D) The specially designed loading assembly made of Nimonic 80 for the MTP fatigue test [Colour figure can be viewed at wileyonlinelibrary.com]

\section{3 | THEORETICAL MODELLING AND DATA INTERPRETATION}

\section{1 | High-temperature UVP model}

\subsection{1 | Constitutive equations}

Considering the geometry constraint effect that the nonstandard MTP specimen has, it is necessary to perform data correlation between the standard and nonstandard small-sized specimens prior to the fatigue testing ${ }^{53-55}$; otherwise, the displacement applied to the MTP specimen will be under- or overestimated, leading to many errors in duplicating the SSFS response. According to the latest literature review, the authors have not yet noticed any published work on this topic using finite element (FE) coupled with an advanced mechanics-based material law to determine the scaling factor, especially in high-temperature LCF testing.
The Chaboche-type UVP material model ${ }^{1,3}$ is adopted in this work to describe the cyclic viscoplastic behavior of FV566 steel at high temperature. The basis for choosing such a model is that the overall high-temperature cyclic behavior is a combination of rate-dependent cyclic plasticity and temperature-dependent creep, which can be well described by Chaboche UVP model. The total deformation is simply assumed to consist of elastic and inelastic (viscoplastic) components, where the latter is a combination of creep and cyclic plasticity. Hence, under small strain deformation, the total strain tensor, $\varepsilon_{i j}$, is composed of both a small recoverable elastic strain tensor, $\varepsilon_{i j}^{e}$, and a large irreversible viscoplastic strain tensor, $\varepsilon_{i j}^{v p}$, such that

$$
\varepsilon_{i j}=\varepsilon_{i j}^{e}+\varepsilon_{i j}^{v p}
$$

According to Hooke's law, the elastic strain is linked to the Cauchy stress tensor, $\sigma_{i j}^{e}$, which can be determined 


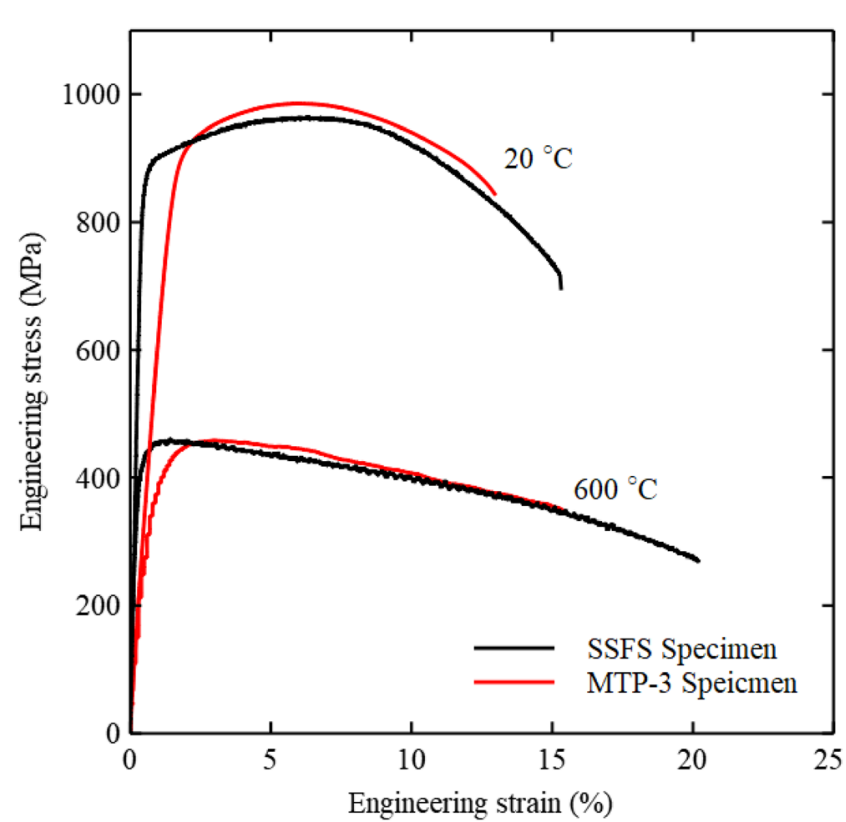

F I G U RE 3 Comparison of engineering stress-strain responses measured from MTP-3 and SSFS tensile tests of FV566 steel at 20 and $600^{\circ} \mathrm{C}$ [Colour figure can be viewed at wileyonlinelibrary. com]

through the following relation for isotropic material, such that

$$
\sigma_{i j}^{e}=\left(2 G I_{i j k l}^{d}+K \delta_{i j} \delta_{k l}\right) \varepsilon_{k l}^{e},
$$

where $G$ and $K$ stand for the shear and bulk moduli, respectively. $I_{i j k l}^{d}$ is the deviatoric part of the fourth-rank identity tensor, $I_{i j k l}$. The current UVP model includes both nonlinear kinematic hardening back stress, $X_{i j}$, related to the motion of center of yield surface, and isotropic hardening drag stress, $R$, related to the yield surface expansion after cyclic plastic deformation. Thus, the inelastic viscoplastic strain-rate flow rule, $\dot{\varepsilon}_{i j}^{v p}$, based on the von Mises yield function, $f_{y}$, can be assumed to be independent of hydrostatic pressure, such that:

$$
\begin{gathered}
f_{y}=J_{2}\left(\sigma_{i j}-X_{i j}\right)-R-\sigma_{k}, \\
\dot{\varepsilon}_{i j}^{v p}=\frac{3}{2} d p \frac{S_{i j}-X_{i j}^{d}}{J_{2}\left(S_{i j}-X_{i j}^{d}\right)},
\end{gathered}
$$

where $\sigma_{k}$ represents the initial cyclic yield stress. $S_{i j}$ is the deviatoric part of Cauchy stress tensor, $\sigma_{i j}$. Following the normality assumption of viscoplasticity, the rate of viscoplastic strain, $\dot{\varepsilon}_{i j}^{v p}$, is normal to the tangent to yield surface, whereas its magnitude is identical to the accumulated effective plastic strain rate, $d p=\left(\frac{2}{3} \dot{\varepsilon}_{i j}^{v p} \dot{\varepsilon}_{i j}^{v p}\right)^{1 / 2}$. The second invariant, $J_{2}$, is defined, such that

$$
J_{2}=\left[3 / 2\left(S_{i j}-X_{i j}^{d}\right)\left(S_{i j}-X_{i j}^{d}\right)\right]^{1 / 2}
$$

where $X_{i j}^{d}$ is the deviatoric part of the back stress, $X_{i j}$, which can be further decomposed into two components, $X_{i j}^{1}$ and $X_{i j}^{2}$, to account for the Bauschinger effect. ${ }^{56} X_{i j}^{1}$ represents the initial kinematic hardening produced after the elastic portion, and $X_{i j}^{2}$ accounts for the kinematic hardening due to the later stage of strain hardening. An Armstrong-Frederick ${ }^{56}$ form has been used to describe the nonlinear evolution of the kinematic hardening, including linear hardening term and dynamic recovery term. The Chaboche kinematic hardening decomposition of the elementary back stress is formulated as follows:

$$
\begin{gathered}
X_{i j}=\sum_{\mathrm{n}=1}^{2} X_{i j}^{n}, \\
\dot{X}_{i j}^{n}=2 / 3 a_{n} b_{n} \dot{\varepsilon}_{i j}^{v p}-a_{n} X_{i j}^{n} d p,
\end{gathered}
$$

where $a_{n}$ and $b_{n}$ are kinematic hardening constants. A nonlinear isotropic hardening stress, ${ }_{R}$, is employed to account for the continuous decelerated cyclic softening, such that

$$
\dot{R}=b(Q-R) d p,
$$

in which $Q$ and $b$ are isotropic hardening parameters. This term represents the saturated value of the isotropic softening stress with increasing of accumulated effective plastic strain and the decay rate, $b$, that leads to the softening saturation, $Q$. The UVP model has been numerically implemented in ABAQUS FE user subroutine UMAT using an implicit integration scheme. ${ }^{1,3}$

\subsection{2 | Determination and calibration of the model parameters}

The cyclic constitutive parameters used in the UVP model are identified from the high-temperature uniaxial LCF test of the SSFS specimen at $600^{\circ} \mathrm{C}^{1}$ The UVP model adopted in this work employs eight parameters in total. The determination of the material parameters follows a step-by-step procedure, with elastic parameter determined initially and followed by the remaining isotropic hardening and kinematic hardening parameters. The parameter $b$ in Equation 8 can be evaluated through the slope in the regression of the plot, whereas $Q$ is determined from the difference in maximum stresses between 
the first and the saturated cycle, as highlighted in Figure 4A. Note that only one isotropic hardening term is adopted for fitting without considering the contributions from the primary and secondary softening as reported in the work by Richard et. al. ${ }^{57}$ The experimental LCF data of the SSFS test at $600^{\circ} \mathrm{C}$ from the tensile part of the initial cycle and the corresponding regression fitting curves are provided in Figure 4B, illustrating the derivations of kinematic hardening parameters $a_{n}$ and $b_{n}$ in Equation 7. More detailed information about the total procedures of how to obtain the initial guess of the UVP parameters can be found in the author's previous work. ${ }^{1-3}$ These initial parameters are then regarded as the starting points to obtain the optimized parameters using a first-order nonlinear least square minimization, ${ }^{1,3}$ where the minimum in the difference between the numerical and the experimental results is sought using two objective functions, that is, (i) experimental hysteresis loop of every cycle and (ii) experimental cyclic softening curve. The total set of the optimized UVP parameters for the FV566 at $600^{\circ} \mathrm{C}$ is given in Table 1.

Uniaxial cyclic viscoplasticity analysis using the UVP model is conducted using the homemade UMAT on a one-element cube model in ABAQUS, in conjunction with the optimized material parameters for model calibration. The calibration procedure is achieved through the comparison between the predicted hysteresis loop and experimentally measured LCF data of the SSFS test for FV566 steel. The comparison of the predicted and measured hysteresis loops at the initial cycle is presented in Figure 5A, followed by the comparison of cyclic softening behavior in Figure 5B.

\section{2 | Data correlation}

\subsection{1 | FE modeling of the nonstandard MTP specimen}

In general, during LCF test for the SSFS uniaxial test, the strain deformation can be achieved directly by the applied displacement dividing the parallel gauge length.

TABLE 1 Optimized material parameters in the UVP model for FV566 at $600^{\circ} \mathrm{C}$

\begin{tabular}{|c|c|c|}
\hline Parameter scopes & Material parameters & Values \\
\hline \multirow[t]{2}{*}{ Elastic } & $\begin{array}{l}\text { Young's modulus, } E \\
\quad(\mathrm{MPa})\end{array}$ & 120,850 \\
\hline & $\begin{array}{l}\text { Initial cyclic yield stress, } \\
\sigma_{k}(\mathrm{MPa})\end{array}$ & 168.41 \\
\hline \multirow{6}{*}{$\begin{array}{l}\text { Isotropic and } \\
\text { kinematic } \\
\text { hardening }\end{array}$} & $\begin{array}{l}\text { Saturated softening stress, } \\
\qquad Q(\mathrm{MPa})\end{array}$ & -122.43 \\
\hline & Softening decay rate, $b(-)$ & 0.87 \\
\hline & Back stress- $1, a_{1}(\mathrm{MPa})$ & 128.61 \\
\hline & Rate of decay- $1, b_{1}(-)$ & 806.02 \\
\hline & Back stress-2, $a_{2}(\mathrm{MPa})$ & 643.63 \\
\hline & Rate of decay- $2, b_{2}(-)$ & 126.36 \\
\hline
\end{tabular}

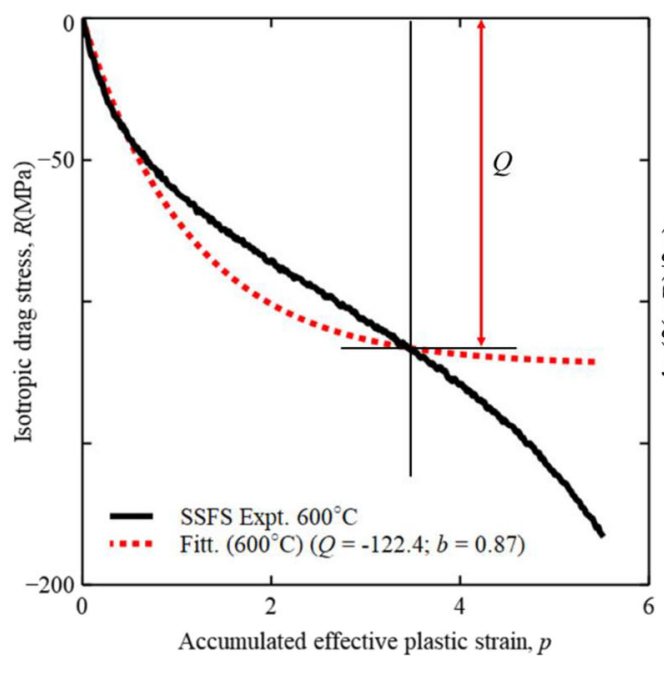

(A)

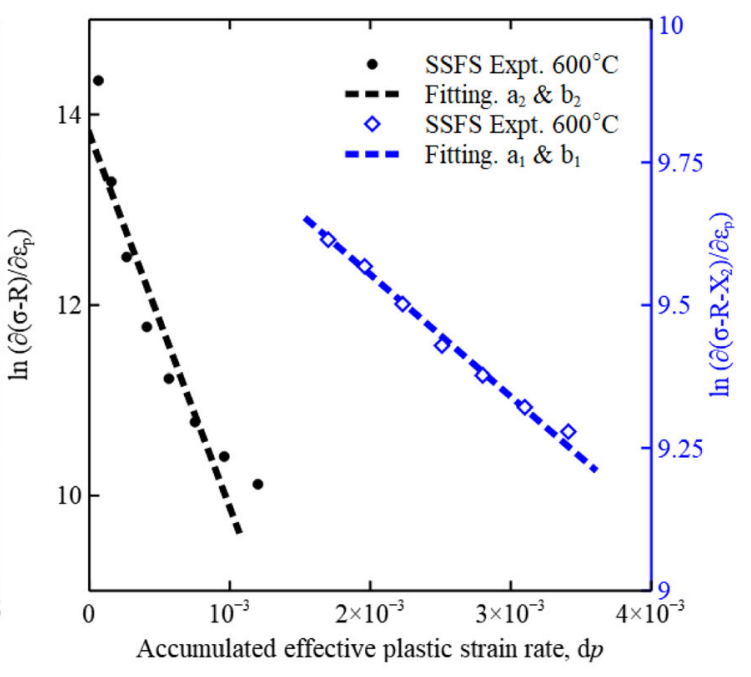

(B)

F I G U RE 4 The determination of (A) isotropic parameters $Q$ and $b$ by fitting of drag stress evolution for description of the yield surface expansion with accumulated effective plastic deformation and (B) kinematic parameters $a_{n}$ and $b_{n}$ for description of the movement of yield surface after material comes into yielding using the SSFS test data of FV566 steel at $600^{\circ} \mathrm{C}$ [Colour figure can be viewed at wileyonlinelibrary.com] 
However, as mentioned above in Section 2.2 for the MTP test, the extensometer is equivalent to be placed at the ends of the fillets (see Figure 2A) to measure the whole deformation including the contributions from the parallel gauge length and transition fillets, leading to the difficulties in obtaining the actual deformation of the parallel gauge length. A useful deformation correlation between the parallel gauge length and transition fillets could not be obtained. Thus, it is necessary to evaluate the scaling factor in order to obtain data correlation between the SSFS and MTP fatigue tests. Additionally, concerning the role of geometry constraint that the nonstandard MTP specimen has, the stress triaxiality in essence within the total effective gauge length plays an important role in high-temperature LCF testing.

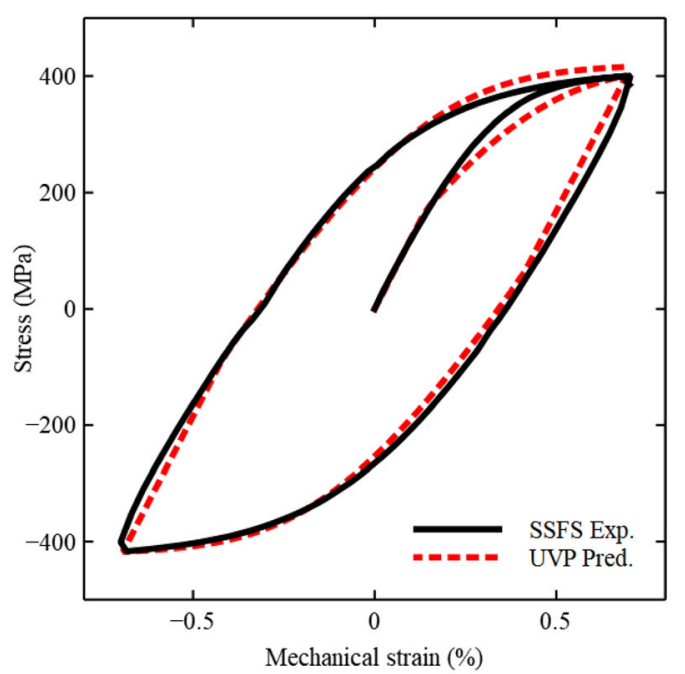

(A)

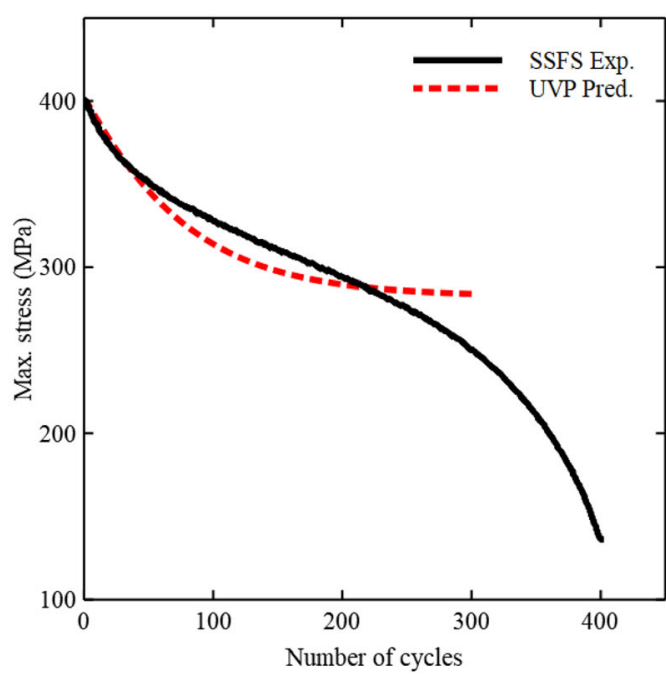

(B)

F I G U RE 5 Comparison of experimental LCF results of the SSFS fatigue test with that predicted using the UVP model. (A) Hysteresis loops for the first loop and (B) the maximum stress evolution with cycles of FV566 steel at $600^{\circ} \mathrm{C}$, a strain range of $\pm 0.7 \%$, and applied strain rate of $0.01 \% \mathrm{~s}^{-1}$ [Colour figure can be viewed at wileyonlinelibrary.com]

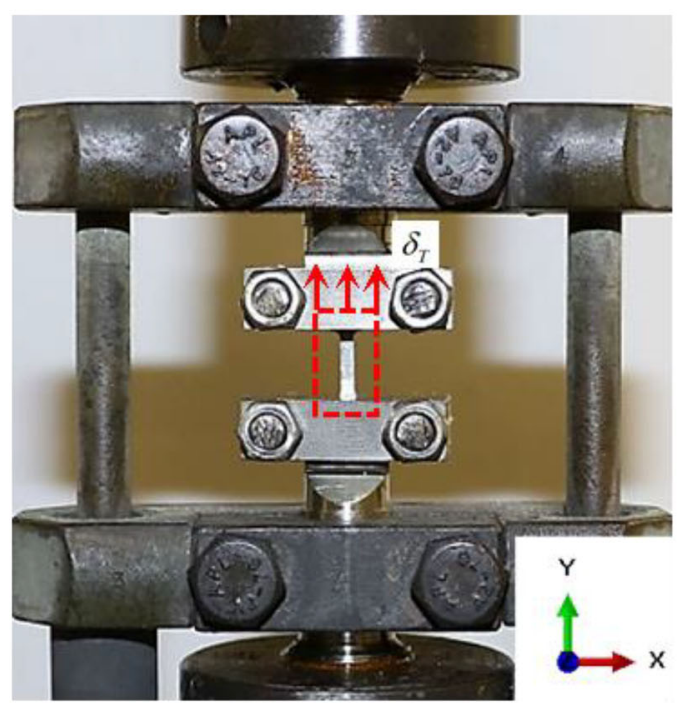

(A)

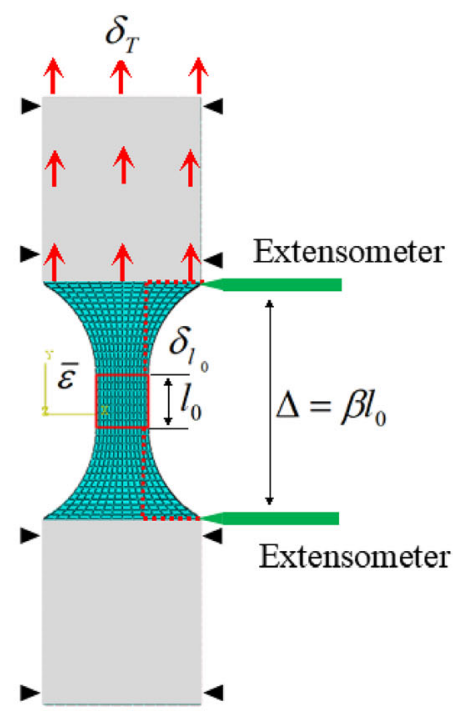

(B)

F I G U RE 6 (A) High-temperature LCF and CF testing setup for the MTP specimen, whereas the total effective gauge length includes the parallel gauge length and the transition fillets. (B) An example of 3D FE model for the MTP specimen, including (i) the methodology for scaling factor identification and (ii) the equivalent location for placing the extensometer [Colour figure can be viewed at wileyonlinelibrary.com] 
To further understand the geometry constraint effect and determine the scaling factor, the authors have established a new methodology that links the MTP FE method with cyclic UVP constitutive model for determination of the scaling factor. The identified scaling factor will be accommodated into high-temperature LCF and CF testing of the MTP specimen for further validation. The identification of scaling factor was simulated through the MTP FE model by comparing with hightemperature LCF data of the SSFS test for FV566 steel at $600^{\circ} \mathrm{C}$. Figure $6 \mathrm{~A}$ shows an example of the MTP LCF testing setup. The corresponding three-dimensional (3D) FE model, mesh, and boundary conditions are given in Figure 6B. C3D8-8 node hexahedral element was utilized in the FE model. The MTP FE model was constrained in an identical way to the clamping condition, as shown in Figure 6A.

In order to minimize the accumulated errors during simulation and obtain more accurate scaling factor, a prior detailed mesh sensitivity study has been particularly studied and analyzed. All the mesh convergence studies have focused on the parallel gauge length region to obtain good resolution in terms of average $\bar{\varepsilon}_{22} \sim \bar{\sigma}_{22}$. Four types of mesh strategies are applied with varying mesh sizes from coarser $(0.2 \mathrm{~mm})$ to finer $(0.05 \mathrm{~mm})$ in the width direction. The results indicate that if the mesh is fine enough, the average response can be supposed to be almost independent of element size. In the aforementioned numerical simulation, a fixed element size of $0.1 \mathrm{~mm}$ has been chosen for meshing the parallel gauge length area.

\subsection{2 | Scaling factor}

In the previous study, the researchers in the work $^{58}$ utilized the reference stress approach to allow the conventional creep data to be obtained from the impression creep test. Based on the similar conception, the authors have proposed a new approach, named as reference strain approach, for the scaling factor identification. An empirical relationship between the parallel gauge length $\left(l_{0}\right)$ and the total effective gauge length $(\Delta)$ is proposed based on the scaling factor, $\beta$, as shown in Figure $6 \mathrm{~B}$. The total effective gauge length can be formulated as follows:

$$
\Delta=\beta l_{0}
$$

The reference average strain in the MTP specimen, $\bar{\varepsilon}$ (equals to $\pm 0.7 \%$ in this study), which is the required mechanical deformation, can be calculated through Equations 10 and 11, such that

$$
\begin{aligned}
& \bar{\varepsilon}=\delta_{T} / \Delta, \\
& \bar{\varepsilon}=\delta_{l_{0}} / \bar{\varepsilon},
\end{aligned}
$$

in which $\delta_{T}$ is the displacement applied to the MTP specimen in both FE model and high-temperature fatigue test. $\delta_{l_{0}}$ is the displacement predicted from the parallel gauge length. Thus, according to the Equations 9-11, the scaling factor, $\beta$, can be formulated as follows:

$$
\beta=\delta_{T} / \delta_{l_{0}}
$$

Therefore, embedding Equation 11 into Equation 12, the displacement, $\delta_{T}$, applied to the MTP specimen in LCF testing, can be finally obtained using the following equation:

$$
\delta_{T}=\bar{\varepsilon} l_{0} \beta
$$

\subsection{3 | Determination of the scaling factor}

A series of numerical simulations were conducted on the nonstandard MTP FE model (see Figure 6B) in order to determine the scaling factor. The material parameters tabulated in Table 1 coupled with the UVP model were accommodated into the MTP FE model. Note that the hysteresis response of the SSFS testing was set as the ultimate target to be fitted by the MTP FE model via varying the scaling factor through trial and error.

Figure 7 shows the comparison of the initial cycle between the experimental LCF result and the predicted result from the MTP FE model using varied scaling factors at $600^{\circ} \mathrm{C}$ for FV566 steel. The predicted average strain-stress responses in the loading direction, $\bar{\varepsilon}_{22} \sim \bar{\sigma}_{22}$, were extracted from the parallel gauge length region of the FE model. Taking MTP-1 as an example, it can be observed from Figure 7A that the hysteresis shape obtained from the numerical model changes as the increase of the tentative scaling factors (e.g., $\beta$ increases from 2.0 to 4.0). The predicted hysteresis curve is capable to appropriately agree with the SSFS data until $\beta$ comes to 4.0. As for the other two MTP specimens in Figure 7B, $\mathrm{C}$, the geometry constraint effect mitigates caused by the increase of $l_{0}$. Consequently, an approximate agreement of hysteresis responses can be achieved by using relatively smaller value of $\beta$, for example, $\beta=3.2$ for MTP-2 and $\beta=2.7$ for MTP-3, respectively. It can be clearly concluded here that the scaling factors could result in varied responses for the MTP fatigue test until an appropriate $\beta$ occurs. This value can be regarded as the determined 


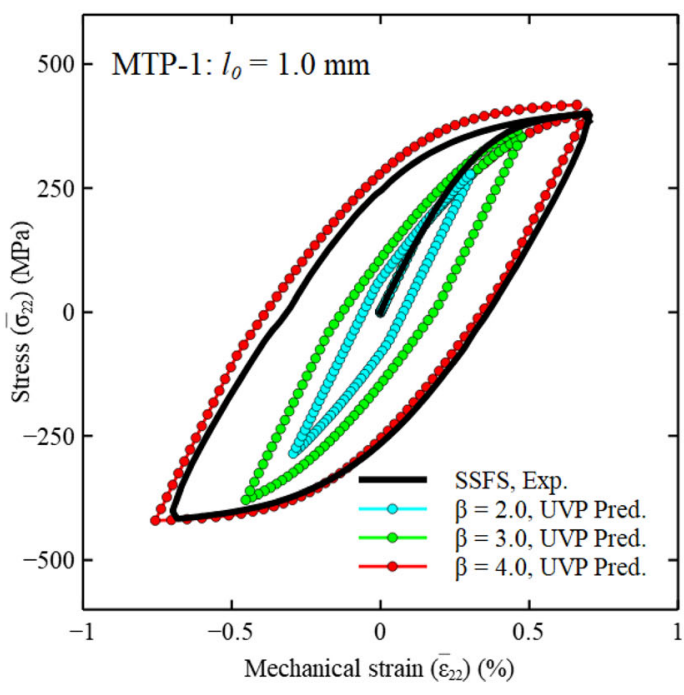

(A)

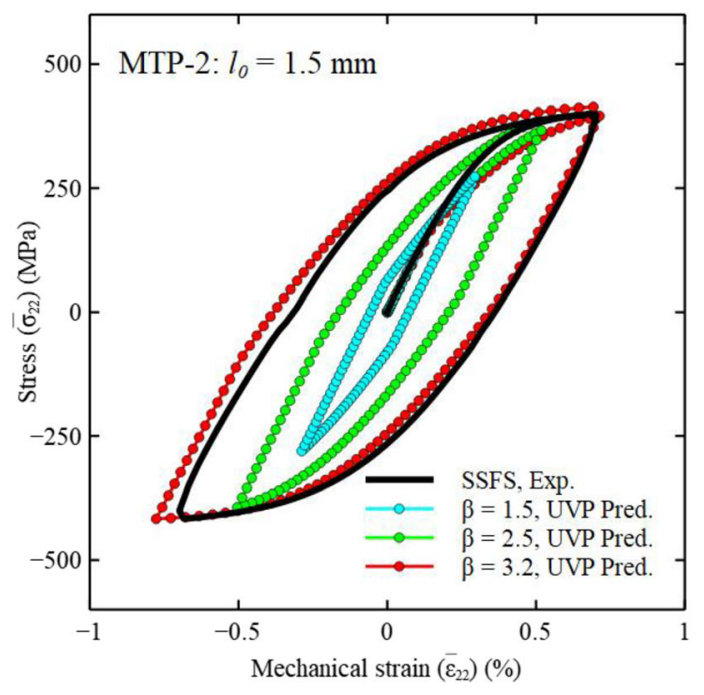

(B)

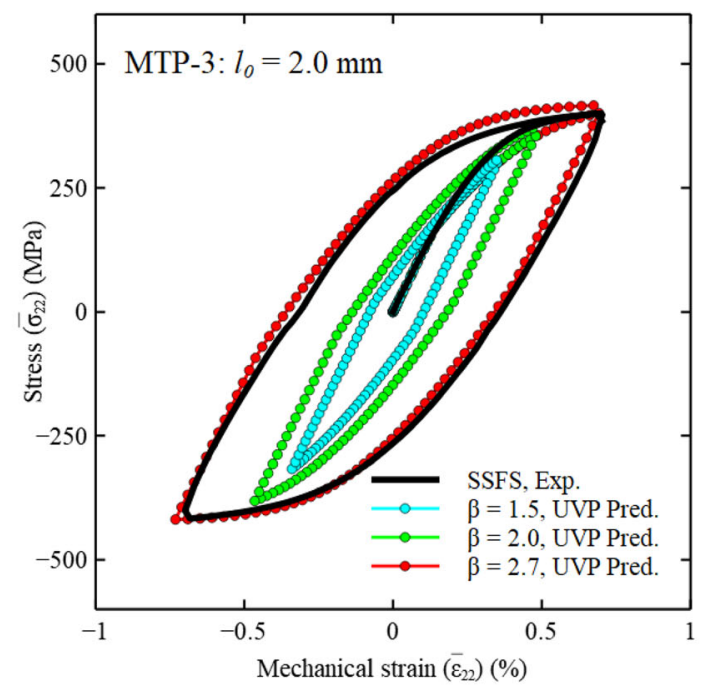

(C)

F I G U RE 7 The comparison with the initial cycle between LCF test data of the SSFS test and the predicted hysteresis responses using varied scaling factors for FV566 steel at $600^{\circ} \mathrm{C}$, (A) MTP-1: $l_{0}=1.0 \mathrm{~mm}$, (B) MTP-2: $l_{0}=1.5 \mathrm{~mm}$, and (C) MTP-3: $l_{0}=2.0 \mathrm{~mm}[\mathrm{Colour}$ figure can be viewed at wileyonlinelibrary.com]

scaling factor (Table 2) to possibly provide the equivalent deformation as the SSFS fatigue test exhibits in this study.

To better understand the geometry constraint effect, Figure 8A provides the curve in terms of finalized scaling factors versus the parallel gauge length, $l_{0}$. Due to the increase of $l_{0}$, the geometry constraint effect on the finalized identified scaling factors (see Table 2) is obvious, for example, the geometry constraint effect becomes weaker as $l_{0}$ increases. Figure 8B shows the computed maximum stress evolution in every cycle until the 58th cycle. It is possible to observe that, when the same material properties are accommodated into the MTP FE models for
TA B LE 2 The determined values of scaling factor, $\beta$, for the MTP specimens based on the UVP model for FV566 steel at $600^{\circ} \mathrm{C}$

\begin{tabular}{ll} 
Specimen & Identified scaling factor, $\boldsymbol{\beta}$ \\
\hline MTP-1: $l_{0}=1.0 \mathrm{~mm}$ & 4.0 \\
MTP-2: $l_{0}=1.5 \mathrm{~mm}$ & 3.2 \\
MTP-3: $l_{0}=2.0 \mathrm{~mm}$ & 2.7 \\
\hline
\end{tabular}

tension and compression testing, the UMAT can gives the inconsistent softening responses due to the different geometry constraint effects in the three MTP specimen. As can be seen from Figure 8B, a continuous predicted 


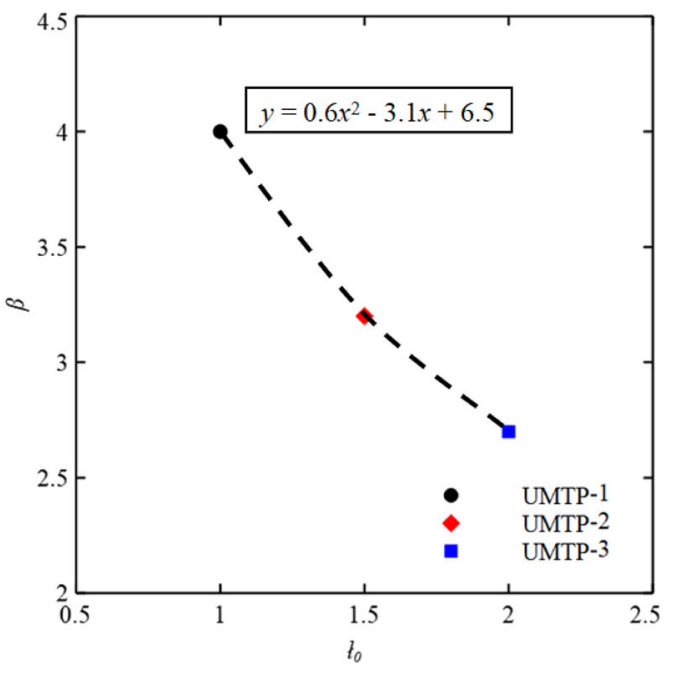

(A)

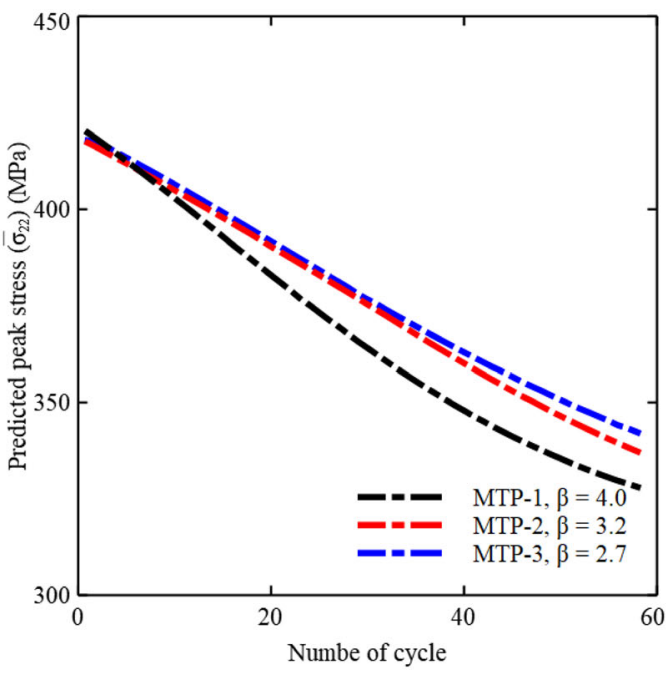

(B)

F I G U RE 8 (A) The determined scaling factor deceases with increasing of $l_{0}$ for the MTP specimen. (B) The predicted peak stress evolution using the determined scaling factors for the MTP specimen of FV566 at $600^{\circ} \mathrm{C}$, indicating the geometry constraint effect on the cyclic response [Colour figure can be viewed at wileyonlinelibrary.com]

cyclic softening (a decrease in the stress amplitude) can be observed for all the MTP specimens, which can be potentially regarded as an implication of accumulated damage and fatigue life. ${ }^{2,18,59,60}$ The largest amount of softening with the highest decay rate can be observed in MTP- 1 when $\beta$ equals to 4.0 , due to the strongest geometry constraint effect. The intermediate case can be found in MTP-2, whereas the amount of softening and decay rate decelerate in MTP-3.

To further examine the mechanical deformation behavior of the three MTP specimens, Figure 9 illustrates the stress and strain distribution in the loading direction using the determined scaling factors (Table 2) for FV566 steel at $600^{\circ} \mathrm{C}$. Note that the spatial distribution is extracted from the maximum applied displacement point of the initial cycle at a strain range of $0.7 \%$. The parallel gauge length regions are marked between the two highlighted lines. In order to make the comparison easier, stress contour plots have been presented using the identical scale. It can be clearly seen from Figure 9A that the highest predicted stress field shows a common uniform pattern within the parallel gauge length with an approximate average value of $\sim 420 \mathrm{MPa}$, which is nearly close to the peak stress that the SSFS fatigue test exhibits at the same loading point (see Figure 7). Additionally, stress heterogeneities can be found at the fillet regions due to the nonuniform geometry and unevenly distributed loading. Similarly, strain contours have also been presented in Figure 9B using the same scale for comparison. As can be seen, the highest strain field in the loading direction exhibits an average deformation of $\sim 0.7 \%$ within the parallel gauge length, which is the expected mechanical deformation of the MTP fatigue test. Once again, strain heterogeneities can be observed at the fillet regions. Thus, according to the numerical perspective in this subsection, it can be confirmed that the proposed reference strain approach coupled with the UVP model is capable to identify the correct scaling factor. Furthermore, by using the MTP testing, it is possible to obtain the similar high-temperature LCF behavior to the SSFS fatigue testing under the equivalent loading conditions.

Due to the occurrence of geometry constraint effect in the nonstandard MTP specimen, the multiaxial stress state within the total effective gauge length can aggravate the accumulated damage and promote crack initiation under LCF test even a relatively uniform stress-strain pattern is achieved at the initial fatigue cycle. Therefore, it is more useful and necessary to examine the accumulated effective plastic strain predicted by the UVP model for the assessment of geometry constraint effect on the subsequent cyclic behavior. Figure $9 \mathrm{c}$ presents the predicted accumulated effective plastic strain distribution until the 58th cycle in the MTP fatigue tests using the determined scaling factors. Note that the accumulated effective plastic strain contours are set to be with the fixed minimum and maximum scale for a better comparison. As can be seen from Figure 9C, the highest accumulation of plastic strain occurs at the center of MTP-1 with the maximum value of $\sim 0.022 \%$, whereas MTP- 2 is capable to carry less amount of plastic strain with the maximum value of $\sim 0.019 \%$. The accumulation of plastic strain distribution becomes extenuative with the 

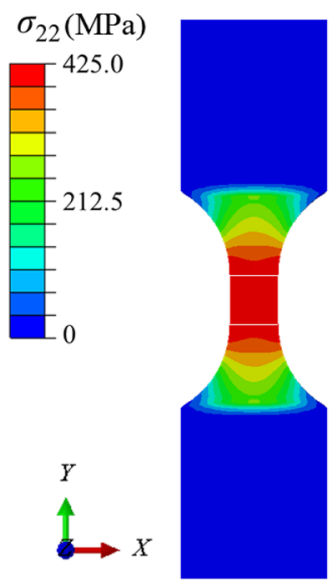

MTP-1: $l_{0}=1.0 \mathrm{~mm} ; \beta=4.0$

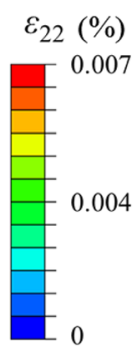

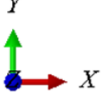

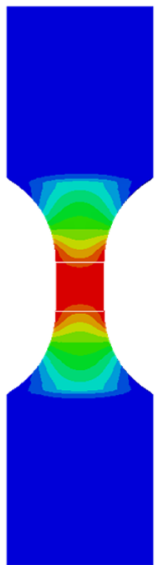

MTP-1: $l_{0}=1.0 \mathrm{~mm} ; \beta=4.0$
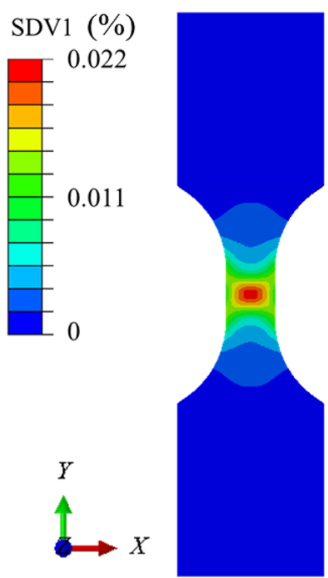

MTP-1 $l_{0}=1.0 \mathrm{~mm} ; \beta=4.0$ $l_{0}=1.5 \mathrm{~mm} ; \beta=3.2$

(A)

MTP-2:

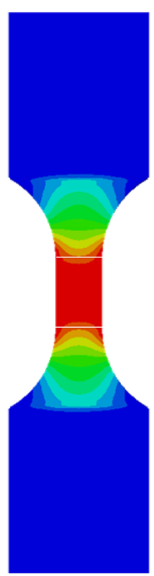
$l_{0}=1.5 \mathrm{~mm} ; \beta=3.2$

(B)
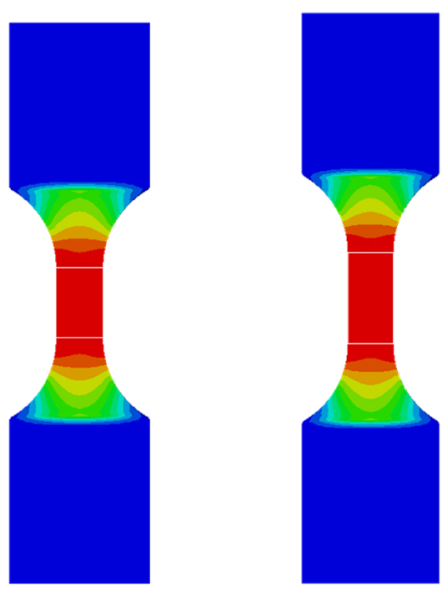

MTP-3:

$l_{0}=2.0 \mathrm{~mm} ; \beta=2.7$

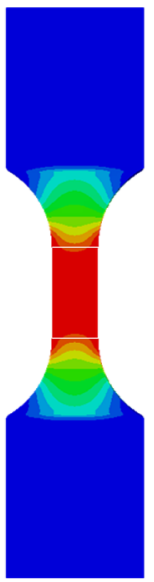

MTP-3:

$l_{0}=2.0 \mathrm{~mm} ; \beta=2.7$

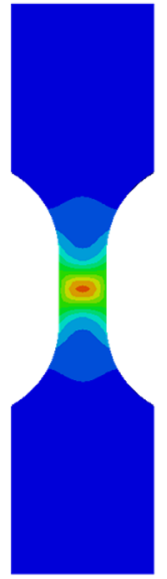

MTP-2:

$l_{0}=1.5 \mathrm{~mm} ; \beta=3.2$

(C)

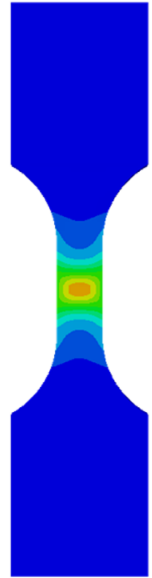

MTP-3: $l_{0}=2.0 \mathrm{~mm} ; \beta=2.7$

F I G U RE 9 The predicted spatial distributions of (A) axial stress, (B) axial strain, and (C) accumulated effective plastic strain distributions until the 58th cycle (peak tensile loading point) at the applied strain of $0.7 \%$ and a strain rate of $0.01 \% \mathrm{~s}^{-1}$ for the MTP specimens using the determined scaling factors in Table 2 [Colour figure can be viewed at wileyonlinelibrary.com] 


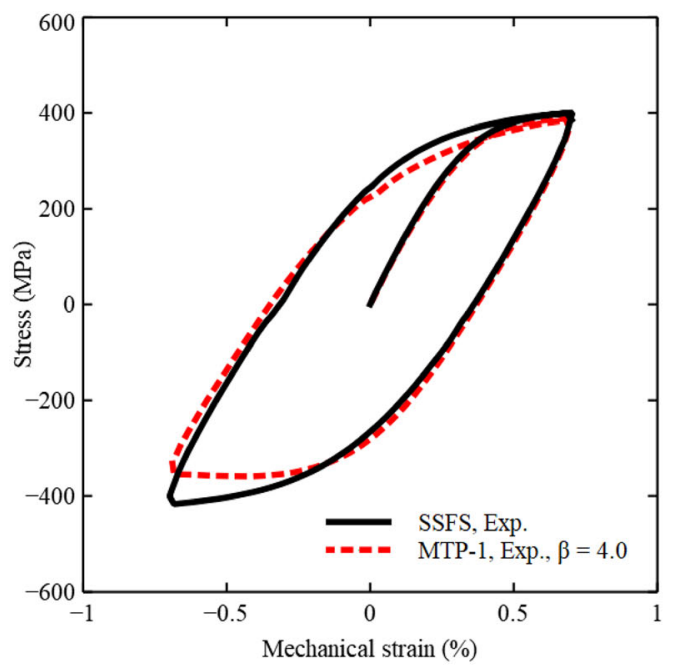

(A)

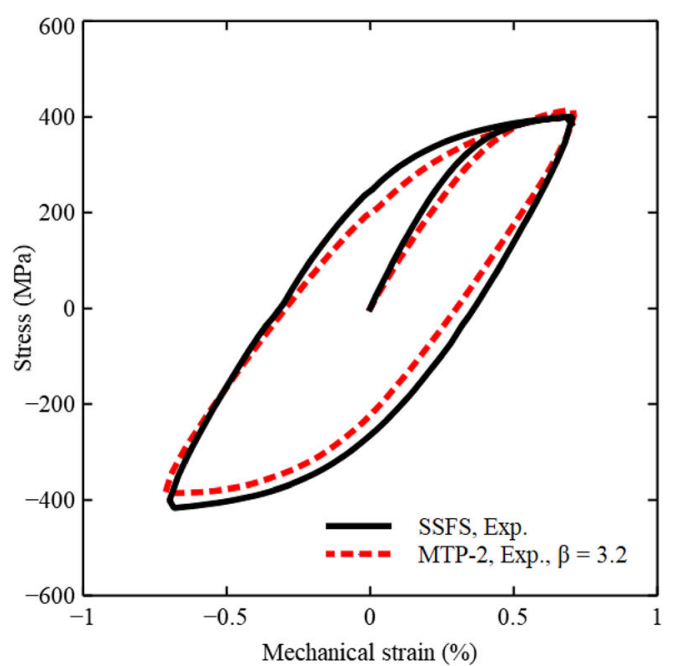

(C)

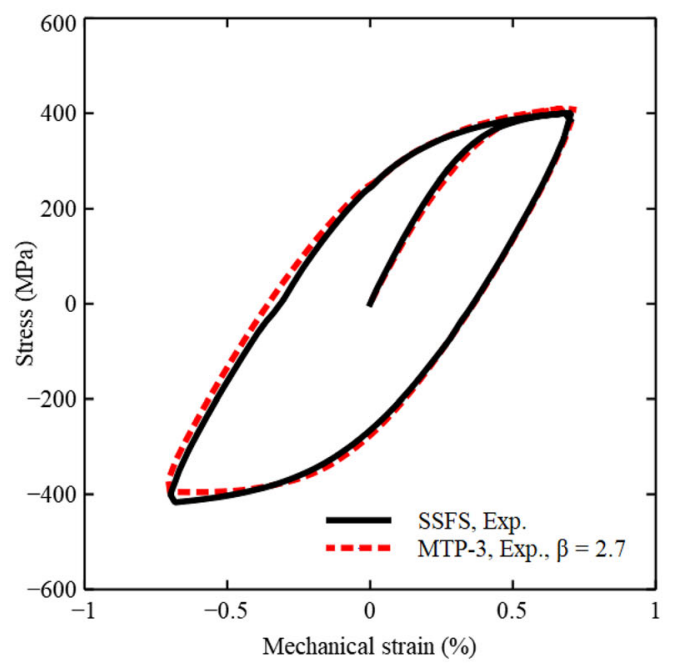

(E)

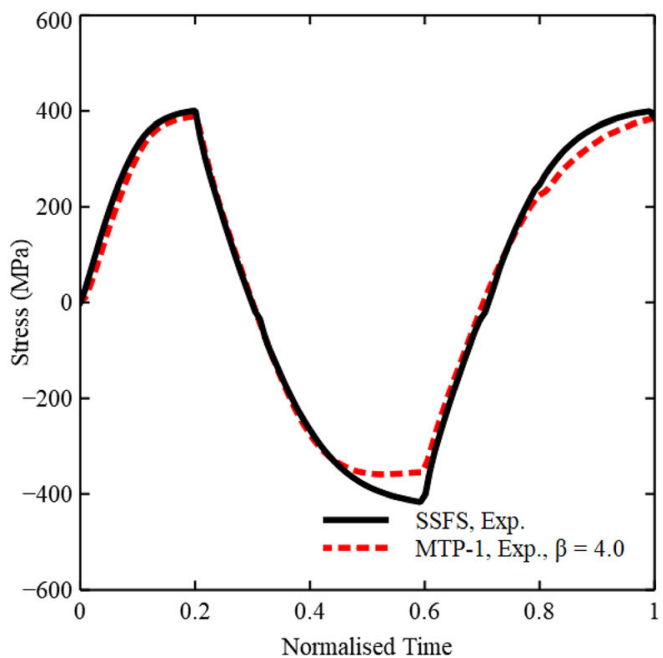

(B)

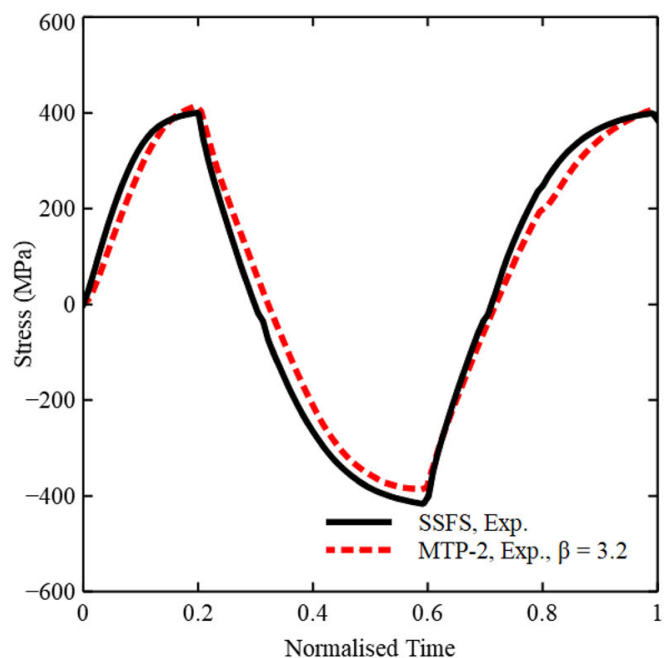

(D)

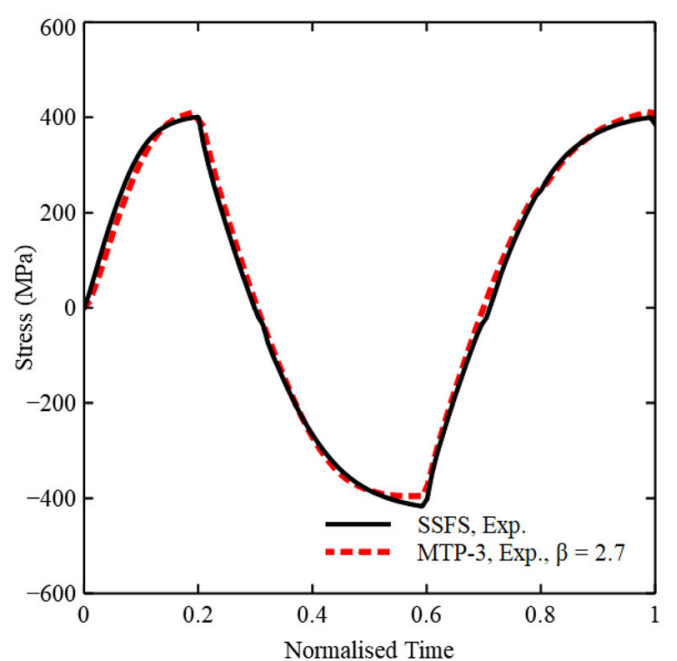

(F)

F I G U RE 10 The comparison of the measured LCF sawtooth hysteresis responses at the initial cycle between the SSFS and MTP fatigue tests for FV566 steel at $600^{\circ} \mathrm{C},(\mathrm{A}, \mathrm{B})$ for MTP-1, (C,D) for MTP-2, and (E,F) for MTP-3. The applied strain rate is $0.01 \% \mathrm{~s}^{-1}$. The deformation correlation was achieved through the determined scaling factor in Table 2 [Colour figure can be viewed at wileyonlinelibrary.com] 
maximum value of $\sim 0.017 \%$ in the case of MTP-3 due to the weakest geometry constraint effect. It can be deduced that, due to the strongest geometry constraint effect, the plastic strain accumulates at the fastest rate in MTP-1, consequently leading to the shortest fatigue life.

From all mentioned in this section, the essence of duplicating the high-temperature LCF deformation using the nonstandard MTP specimen is the identification of scaling factor based on a reliable mechanics-based technique. These simulations have proved that the existing of scaling factor is mainly attributed to the geometry constrain effect that the nonstandard MTP specimen has. Meanwhile, these simulations also reveal the underlying mechanism of the MTP specimen design principle from the perspective of mechanics. The numerical findings based on the UVP model will be checked through the experimental LCF test at $600^{\circ} \mathrm{C}$ for FV566 steel in the following sections to demonstrate the testing methodology developed in this study.

\section{4 | RESULTS}

\section{1 | MTP specimen LCF sawtooth test}

Figure 10 presents the comparison of the experimentally measured stress-strain hysteresis responses subjected to the sawtooth loading at the first cycle between the SSFS and MTP fatigue tests for FV566 steel at $600^{\circ} \mathrm{C}$. The accuracy of the first hysteresis loop under high-temperature LCF test is particularly important as it can be used to determine the elastic and kinematic parameters, for example, $E, \sigma_{k}, a_{n}$, and $b_{n}$ for Chaboche unified viscoplastic model in this paper. ${ }^{1-3}$ As can be seen from Figure 10 (left), the reversible hysteresis responses measured from the MTP fatigue tests using the determined scaling factors show an approximate agreement with the SSFS fatigue test under the equivalent loading conditions, particularly, for MTP-3 with the weakest geometry constraint effect. In addition, the hysteresis loops of the MTP fatigue test exhibit a similar dynamic strain hardening behavior to that of the SSFS fatigue test. To enable a direct comparison of the temporal stress evolution behavior between the SSFS and MTP fatigue test, the stress data versus normalized time are plotted in Figure 10 (right), again, showing an approximate agreement.

Some of the important experimentally measured parameters are further calculated and compared in Table 3 between the MTP and SSFS fatigue tests, including Young's modulus $(E)$, initial cyclic yield stress $\left(\sigma_{k}\right)$, and cyclic strain hardening exponent $\left(n^{\prime}\right)$, together with the cyclic strength coefficient $\left(K^{\prime}\right)$ calculated according to the Ramberg-Osgood relationship. ${ }^{61}$ Obviously, the mechanical properties obtained from MTP-3 fatigue test can approximately agree with these derived from the SSFS fatigue test, as shown in Table 3. Thus, it is concluded that the scaling factors determined from the UVP FE method can be used with confidence to correlate the cyclic data between the SSFS and MTP fatigue tests. The measured cyclic strain-stress data from the MTP test at high temperature can be adopted to evaluate some of the essential parameters that required by the UVP model.

\section{2 | MTP specimen LCF dwell test}

The CF dwell test at high temperature can be used to determine the viscous parameters, that is, viscoplastic resistance and viscoplastic exponent within the Chaboche UVP model, based on Cottrell's stress partition method. ${ }^{1,3}$ Here, only CF dwell test using MTP-3 specimen at $600^{\circ} \mathrm{C}$ is carried out and compared with the SSFS dwell test ${ }^{1}$ due to the weakest geometry constraint effect that MTP-3 has, as indicated in Section 3.2.3. Once again, as can be seen from Figure 11A, the cyclic response from MTP-3 specimen can roughly duplicate the behavior of the SSFS dwell fatigue test under the equivalent loading conditions. However, a mismatch can be observed in the latter tension-loading stage probably due to the slippage between the clamps and specimen. Obvious significant stress relaxation with a dwell period of $150 \mathrm{~min}$ is observed in MTP-3 dwell fatigue test as expected. The measured stress evolutions versus normalized time for both the MTP and SSFS tests are presented in Figure 11B. Slight difference can be seen at the maximum tension and compression loading points. During the dwell period at the same applied mechanical strain of $0.7 \%$, the stress relaxation of MTP-3 test is almost the same as that from the SSFS test. Satisfactory comparison is obtained for the influence of hold time on the peak stresses. Thus, the viscous parameters can also be assessed based on the stress relaxation data measured from MTP-3 specimen at high temperature.

TABLE 3 Comparison of the material parameters based on Ramberg-Osgood relation derived from the SSFS and the MTP LCF tests for FV566 steel at $600^{\circ} \mathrm{C}$

\begin{tabular}{lllll} 
Specimen & $\boldsymbol{E}(\mathbf{M P a})$ & $\sigma_{\boldsymbol{k}}(\mathbf{M P a})$ & $\boldsymbol{K}^{\prime}(\mathbf{M P a})$ & $\boldsymbol{n}^{\prime}$ \\
SSFS & 120,850 & 168.41 & 299.6 & 6.48 \\
MTP-1 & 120,420 & 166.53 & 294.3 & 6.32 \\
MTP-2 & 118,460 & 154.27 & 299.1 & 6.57 \\
MTP-3 & 120,421 & 168.31 & 299.3 & 6.47 \\
\hline
\end{tabular}




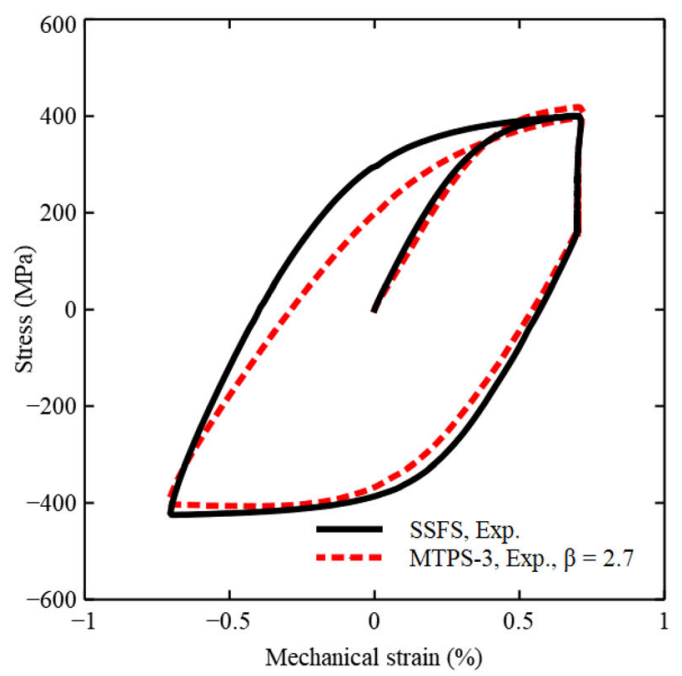

(A)

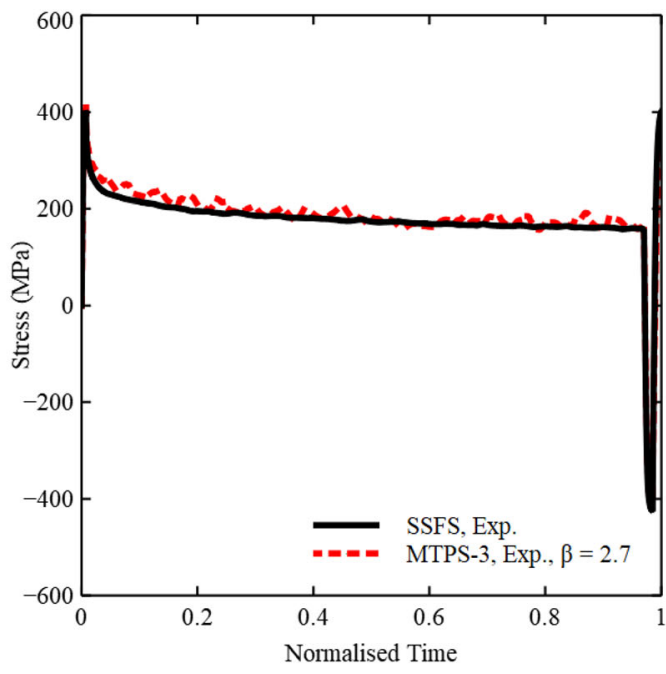

(B)

F I G U RE 11 The comparison of the measured and predicted CF dwell-type response at the first cycle between the SSFS and MTP-3 dwell fatigue test for FV566 steel at $600^{\circ} \mathrm{C}$, (A) hysteresis response and (B) stress evolution versus normalized time, under the applied strain rate of $0.01 \% \mathrm{~s}^{-1}$. The hold period is $150 \mathrm{~min}$ [Colour figure can be viewed at wileyonlinelibrary.com]

\section{3 | Cyclic softening and fatigue life}

The cyclic softening behavior is also essential for the isotropic parameter identification $(Q$ and $b$ in Equation 8$)^{1-3}$ in Chaboche UVP model and damage parameters. ${ }^{62}$ Thus, the measured peak stress evolution versus fatigue life $(N)$ subjected to the sawtooth and dwell-type loadings is given in Figure 12. Similarly, significant cyclic softening is observed in all the MTP fatigue tests with different magnitude levels and rates, as the primary mechanism of cyclic softening in the investigated material is low angle boundary dislocation annihilation. ${ }^{63,64}$ In general, the trends of the measured peak stress evolution in every cycle under the sawtooth loading are similar to the cyclic response of the SSFS fatigue test. However, cyclic softening and fatigue life of the MTP tests exhibit a strong geometry dependency. For example, for the fatigue tests under the sawtooth loading, MTP-3 specimen with the weakest geometry constraint effect can give the closest fatigue life to that of the SSFS fatigue test, whereas MTP-2 is the intermediate case. The shortest fatigue life can be observed in MTP-1 due to the strongest geometry constraint effect. The fatigue life of MTP-3 subjected to the dwell-type loading is significantly lower than that of MTP-3 test under the sawtooth loading because the hold dwell effect can aggravate the damage accumulation. ${ }^{1,3,63,64}$ Table 4 tabulates the comparison of fatigue life $\left(N_{f}\right)$ for all the tests within this work.

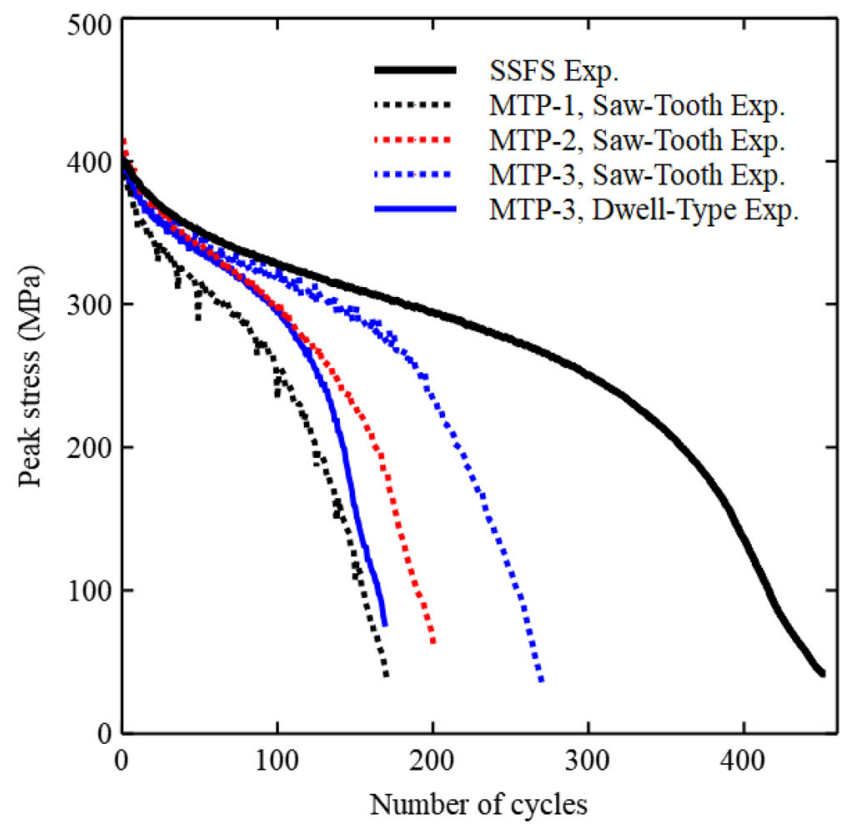

F I G U RE 12 The comparison of cyclic softening and fatigue life obtained from the experimental SSFS and MTP tests for FV566 at $600^{\circ} \mathrm{C}$ under the applied strain range of $\pm 0.7 \%$ and a strain rate of $0.01 \% \mathrm{~s}^{-1}$ [Colour figure can be viewed at wileyonlinelibrary.com]

\section{5 | DISCUSSION, CONCLUSIONS, AND FUTURE WORK}

In this work, a special clamping feature is designed and manufactured, which is capable to produce a rigid 
T A B LE 4 Comparison of the number of cycles to failure, $N_{f}$, obtained from the MTP and SSFS fatigue tests for FV566 at $600^{\circ} \mathrm{C}$

\begin{tabular}{lllll} 
Specimen type & $\dot{\varepsilon}$ & $\varepsilon$ & Waveform & $\boldsymbol{N}_{\boldsymbol{f}}$ \\
SSFS & $0.01 \% \mathrm{~s}^{-1}$ & $\pm 0.7 \%$ & Sawtooth & 457 \\
MTP-1 & & & & 172 \\
MTP-2 & & & 200 \\
MTP-3 & & & & 271 \\
MTP-3 & & & Dwell type & 170 \\
\hline
\end{tabular}

displacement transfer and ensure alignment for the MTP specimen, in order to minimize the detrimental effect of bending torsional on the high-temperature LCF testing. Due to the small-sized specimen used in this work, the uniform uniaxial strain deformation is difficult to be directly measured from the parallel gauge length. Thus, a scaling factor, which can be used to realize the fatigue data correlation between the conventional standardized and nonstandard MTP specimens, is proposed based on the reference strain approach. The UVP FE model coupled with the identified high-temperature LCF material properties for the FV566 steel is employed to determine the scaling factor under the required mechanical deformation. The feasibility of the nonstandard MTP testing has been further checked via the fully reversed sawtooth and CF dwell-type tests for FV566 steel at $600^{\circ} \mathrm{C}$. The key conclusions can be summarized as follows:

- A high-temperature LCF testing method using a thinplate miniaturized specimen, MTP, is successfully developed.

- The UVP model has shown to be capable to represent the cyclic plasticity behavior using the fatigue test data for a turbine steel at $600^{\circ} \mathrm{C}$.

- The geometry-dependent scaling factor of the MTP specimen is determined by FE analysis coupled with an advanced mechanics-based material model based on the reference strain approach.

- A comparability of LCF and CF responses between the MTP and standard-sized specimen tests is demonstrated.

Further investigations should be carried out to continuously improve the testing rigs, such as new design of the clamp fixtures to reduce the slippage. Moreover, more metallographic investigations are needed to identify the failure mechanism because the MTP fatigue test at high temperature is prone to have oxidation damage, leading to premature fatigue crack initiation and the reduction of fatigue life. Although the possible trend for the size effect has been introduced in the work, ${ }^{65,66}$ available data are still rather scare, especially for the size effect at high temperature. More investigations should be carried out in this scope as well in the future.

\section{ACKNOWLEDGMENTS}

This work is supported by the Engineering and Physical Sciences Research Council UK (grant number: EP/N509991/1). This research was also supported by the National Natural Science Foundation of China (grant number: 51875461).

\section{AUTHOR CONTRIBUTIONS}

Ming Li: Conceptualization, methodology, software, formal analysis, investigation, data curation, writingoriginal draft. Shane Maskill: Experiments. Zhixun Wen: Review and editing. Zhufeng Yue: Writingreview and editing, supervision, project administration, funding acquisition. Wei Sun: Conceptualization, methodology, writing-review and editing, supervision, project administration, funding acquisition.

\section{DATA AVAILABILITY STATEMENT}

The data that support the findings of this study are available from the corresponding author upon reasonable request.

\section{NOMENCLATURE}

$l_{0} \quad$ the parallel gauge length

$d \quad$ the parallel gauge width

$\varepsilon_{i j} \quad$ total strain tensor

$\varepsilon_{i j}^{e} \quad$ elastic strain tensor

$\varepsilon_{i j}^{v p} \quad$ viscoplastic strain tensor

$\dot{\varepsilon}_{i j}^{p p} \quad$ viscoplastic strain tensor rate

$\delta_{i j} \quad$ Kronecker delta

$\sigma_{i j}^{e} \quad$ Cauchy stress tensor

$I_{i j k l}, I_{i j k l}^{d} \quad$ identity tensor and deviatoric part

${ }_{G},{ }_{K} \quad$ shear and bulk moduli

$J_{2} \quad$ the second invariant

$f_{y} \quad$ von Mises yield function

$S_{i j} \quad$ the deviatoric stress of Cauchy stress tensor

$X_{i j}, X_{i j}^{d}$ nonlinear kinematic hardening back-stress, deviatoric part of back stress

$X_{i j}^{1}, X_{i j}^{2} \quad$ initial and later kinematic hardening back stress

$R \quad$ isotropic hardening drag stress

$P \quad$ accumulated effective plastic strain

$\mathrm{d} p \quad$ accumulated effective plastic strain rate

$\sigma_{k} \quad$ initial cyclic yield stress

$a_{n}, b_{n} \quad$ kinematic hardening parameters

$Q, b \quad$ isotropic hardening parameters

$\Delta \quad$ total effective gauge length

$\beta \quad$ scaling factor 
$\delta_{T} \quad$ total displacement applied to the miniature specimen during fatigue test

$\delta_{l_{0}} \quad$ predicted displacement in the parallel gauge length

$\bar{\varepsilon} \quad$ the average strain deformation in the parallel gauge length

E $\quad$ Young's modulus

$n^{\prime} \quad$ cyclic strain hardening exponent

$K^{\prime} \quad$ cyclic strength coefficient

$N, N_{f} \quad$ number of cycles and number of cycles to failure

\section{REFERENCES}

1. Rae Y, Benaarbia A, Hughes J, Sun W. Experimental characterization and computational modelling of cyclic viscoplastic behavior of turbine steel. Int J Fatigue. 2019;124: 581-594.

2. Li M, Barrett AR, Scully S, Harrison MN, Leen SB, O'Donoghue PE. Cyclic plasticity of welded P91 material for simple and complex power plant connections. Int J Fatigue. 2016;87:391-404.

3. Li M, Benaarbia A, Morris A, Sun W. Assessment of potential service-life performance for MarBN steel power plant header under flexible thermomechanical operations. Int J Fatigue. 2020;135:105565

4. Rhys-Jones TN, Cunningham TP. The influence of surface coatings on the fatigue behavior of aero engine materials. Surf Coat. 1990;42(1):13-19.

5. Kumar K, Madhusoodanan K, Singh RN. Miniature test techniques for life management of operating equipment. Nucl Eng. 2017;323:345-358.

6. Hyde TH, Sun W. A novel, high-sensitivity, small specimen creep test. J Strain Anal Eng Des. 2009;44(3):171-185.

7. Chen H, Jackson GA, Sun W. An overview of using small punch testing for mechanical characterization of MCrAlY bond coats. J Therm Spray Technol. 2017;26(6):1222-1238.

8. Chen H, Hyde TH. Use of multi-step loading small punch test to investigate the ductile-to brittle transition behavior of a thermally sprayed CoNiCrAlY coating. Mater Sci Eng A. 2017;680: 203-209.

9. Hyde TH, Sun W, Williams JA. The requirements for and the use of miniature test specimens to provide mechanical and creep properties of materials: a review. Int Mater Rev. 2007; 52(4):213-255.

10. Bruchhausen M, Turba K, de Haan F, Hähner P, Austin T, de Carlan Y. Characterization of a $14 \mathrm{Cr}$ ODS steel by means of small punch and uniaxial testing with regard to creep and fatigue at elevated temperatures. J Nucl Mater. 2014;444(1-3): 283-291.

11. Zhao L, Wang X, Xu L, Han Y, Jing H. Fatigue performance of Hastelloy $\mathrm{X}$ at elevated temperature via small punch fatigue test. Theor Appl Fract Mech. 2021;116:103118.

12. Yang S, Ling X, Zheng Y, Ma R. Creep life analysis by an energy model of small punch creep test. Maternite. 2016;91: 98-103.

13. Cizek J, Kovarik O, Cupera J, et al. Measurement of mechanical and fatigue properties using unified, simple-geometry specimens: cold spray additively manufactured pure metals. Surf Coat. 2021;412:126929.

14. Wen W, Sun W, Becker AA. A two-material miniature specimen test method and the associated inverse approach for high temperature applications. Theor Appl Fract Mech. 2019; 99:1-8.

15. Zhou J, Barrett RA, Leen SB. A physically-based method for predicting high temperature fatigue crack initiation in $\mathrm{P} 91$ welded steel. Int J Fatigue. 2021;153:106480.

16. Kim JH, Ro U, Lee H, Kang SJ, Lee BH, Kim MK. A direct assessment of creep life based on small punch creep test. Theor Appl Fract Mech. 2019;104:102346.

17. Song $\mathrm{K}$, Zhao L, Xu L, Han Y, Jing H. Experimental and numerical analysis of creep and damage behavior of $\mathrm{P} 92$ steel by small punch tests. Theor Appl Fract Mech. 2019;100: 181-190.

18. Li M, Sun FW, Li DF, O'Donoghue PE, O'Dowd NP, Leen SB. The effect of ferrite phases on the micromechanical response and crack initiation in the inter-critical heat-affected zone of a welded 9Cr martensitic steel. Fatigue Fract Eng Mater Struct. 2018;41(6):1245-1259.

19. Gussev MN, Howard RH, Terrani KAT, Field KG. Sub-size tensile specimen design for in-reactor irradiation and postirradiation testing. Nucl Eng Des. 2017;320:298-308.

20. Sastry DH. Impression creep technique - an overview. Mater Sci Eng A. 2005;409(1-2):67-75.

21. Gupta R, Daniel BSS. Impression creep behaviour of ultrasonically processed in-situ Al3Ti reinforced aluminium composite. Mater Sci Eng A. 2018;733:257-266.

22. Kumar S, Ramteke S, Chelik S, Vanitha C. Creep behavior of Al-Si-Mg alloy by hot impression creep test. Mater Today: Proc. 2021;41:1207-1211.

23. Dobeš F, Milička K. On the Monkman-Grant relation for small punch test data. Mater Sci Eng A. 2002;336(1-2):245-248.

24. Bruchhausen M, Holmström S, Simonovski I, et al. Recent developments in small punch testing: tensile properties and DBTT. Theor Appl Fract Mech. 2016;86:2-10.

25. Simonovski I, Holmstrom S, Bruchhausen M. Small punch tensile testing of curved specimens: finite element analysis and experiment. Int J Mech Sci. 2017;120:204-213.

26. Altstadt E, Houska M, Simonovski I, Bruchhausen M, Holmström S, Lacalle R. On the estimation of ultimate tensile stress from small punch testing. Int J Mech Sci. 2018; 136:85-93.

27. Pham HT, Iwamoto T. An evaluation of fracture properties of type-304 austenitic stainless steel at high deformation rate using the small punch test. Int J Mech Sci. 2018;144: 249-261.

28. Rouse JP, Simonelli M, Hyde CJ. On the use of small ring testing for the characterization of elastic and yield material property variation in additively manufactured materials. Addit Manuf. 2020;36:101589.

29. Yu HY, Zhou GY, Tu ST, Zhang FK. A new approach to evaluate material creep properties by C-shape ring specimen with fixed constraints. Int J Press Vessel pip. 2021; 191:104357.

30. Kazakeviciute J, Rouse JP, de Focatiis DSA, Hyde CJ. The development of a novel technique for small ring specimen tensile testing. Theor Appl Fract Mech. 2019;99:131-139. 
31. Naumenko K, Gariboldi E. Experimental analysis and constitutive modeling of anisotropic creep damage in a wrought agehardenable Al alloy. Eng Fract Mech. 2022;259:108119.

32. Wen W, Jackson GA, Li H, Sun W. An experimental and numerical study of a CoNiCrAlY coating using miniature specimen testing techniques. Int J Mech Sci. 2019;157:348-356.

33. Leclerc N, Khosravani A, Hashemi S, Miracle DB, Kalidindi SR. Correlation of measured load-displacement curves in small punch tests with tensile stress-strain curves. Acta Mater. 2021;204:116501.

34. Lee JM, Hwang JH, Kim YJ, Kim JW. Predicting ductile fracture of cracked pipes using small punch test data. Eur J Mech a Solids. 2021;87:104211.

35. Peng YQ, Cai LX, Chen H, Bao C. A new method based on energy principle to predict uniaxial stress-strain relations of ductile materials by small punch testing. Int J Mech Sci. 2018; 138-139:244-249.

36. Li YZ, Stevens P, Sun MC, Zhang CQ, Wang W. Improvement of predicting mechanical properties from spherical indentation test. Int J Mech Sci. 2016;117:182-196.

37. Wang H, Wang QD, Boehlert CJ, et al. The impression creep behavior and microstructure evolution of cast and cast-thenextruded Mg-10Gd-3Y-0.5Zr. Mater Sci Eng A. 2016;649: 313-324.

38. Sakthivel T, Sasikala G, Vasudevan M. Role of microstructures on heterogeneous creep behaviour across P91 steel weld joint assessed by impression creep testing. Mater Charact. 2020;159: 109988.

39. Zhuang FK, Tu ST, Zhou GY, Wang QQ. Assessment of creep constitutive properties from three-point bending creep test with miniaturized specimens. J Strain Anal Eng Des. 2014;49(7): 482-491.

40. Yang SS, Cao Y, Ling X, Qian Y. Assessment of mechanical properties of Incoloy $800 \mathrm{H}$ by means of small punch test and inverse analysis. J Alloys Compd. 2017;695:2499-2505.

41. Džugan J, Procházka R, Konopík P, Sokolov MA, Lucon E. Small Specimen Test Techniques. Vol. 6th. ASTM International; 2015:12-29.

42. Džugan J, Konopik P, Rund M, Prochazka R. Determination of local tensile and fatigue properties with the use of sub-sized specimens. PVP Conference ASME. 2015;56925:V01AT01A066.

43. Džugan J, Procházka R, Konopík P. Low cycle fatigue tests with the use of miniaturized test specimens. PVP Conference ASME. 2017;57908:V01AT01A072.

44. Lancaster RJ, Illsley HW, Hurst R, Jeffs S, Baxter G. A novel approach to small punch fatigue testing. Key Eng Mater. 2017; 734:61-69.

45. Lancaster RJ, Jeffs SP, Illsley HW, Argyrakis C, Hurst RC, Baxter GJ. Development of a novel methodology to study fatigue properties using the small punch test. Mater Sci Eng A. 2019;748:21-29.

46. Nozaki M, Sakane M, Fujiwara M. Low cycle fatigue testing using miniature specimens. Int J Fatigue. 2020;137:105636.

47. Nogami S, Hasegawa A, Yamazaki M. Fatigue properties of ferritic/martensitic steel after neutron irradiation and helium implantation. Nucl Mater Energy. 2020;24:100764.
48. Pahlavanyali S, Rayment A, Roebuck B, Drew G, Rae CMF. Thermo-mechanical fatigue testing of superalloys using miniature specimens. Int J Fatigue. 2008;30(2):397-403.

49. Dai CY, Zhang B, Xu J, Zhan GP. On size effects on fatigue properties of metal foils at micrometer scales. Mater Sci Eng A. 2013;575:217-222.

50. Kohno Y, Kohyama A, Hamilton ML, Hirose T, Katoh Y, Garner FA. Specimen size effects on the tensile properties of JPCA and JFMS. J Nucl Mater. 2000;283:1014-1017.

51. Howard C, Frazer D, Lupinacci A, et al. Investigation of specimen size effects by in-situ microcompression of equal channel angular pressed copper. Mater Sci Eng A. 2016;649:104-113.

52. Turnbull A, Zhou S. Comparative evaluation of environment induced cracking of conventional and advanced steam turbine blade steels. Part 1: Stress corrosion cracking. Corros Sci. 2010; 52(9):2936-2944.

53. Gussev M, Busby JT, Field KG, Sokolov MA. Role of scale factor during tensile testing of small specimens. In: Sokolov M, Lucon E, eds. Small Specimen Test Techniques. Vol. 6th. ASTM International; 2015.

54. Chernobaeva AA, Medvedev KI, Zhurko DA, et al. Scale factor of standard and mini Charpy specimens from VVER-1000 RPV materials. Int J Press Vessel Pip. 2016;145:23-28.

55. Callaghan MD, Humphries SR, Law M, Bendeich $\mathrm{P}$, Yeung WY. Special testing equipment and validation of measurement methodologies for high temperature low cycle fatigue testing of miniature metallic specimens. Exp Mech. 2016;56(6): 1039-1050.

56. Frederick CO, Armstrong PJ. A mathematical representation of the multiaxial Bauschinger effect. Mater High Temp. 2007; 24(1):11-26.

57. Barrett RA, O'Hara EM, O'Donoghue PE, Leen SB. Hightemperature low-cycle fatigue behavior of MarBN at $600 \mathrm{C}$. J Press Vessel Technol. 2016;138(4):041401.

58. Hyde TH, Yehia KA, Becker AA. Interpretation of impression creep data using a reference stress approach. Int J Mech Sci. 1993;35(6):451-462.

59. Sweeney CA, O'Brien B, Dunne FPE, McHugh PE, Leen SB. Strain-gradient modelling of grain size effects on fatigue of CoCr alloy. Acta Mater. 2014;78:341-353.

60. Barrett RA. An improved unified viscoplastic constitutive model for strain-rate sensitivity in high temperature fatigue. Int J Fatigue. 2013;48:192-204.

61. Nieslony A, Chalid D, Kaufmann H, Krug P. New method for evaluation of the Manson-Coffin-Basquin and RambergOsgood equations with respect to compatibility. Int $J$ Fatigue. 2008;30(10-11):1967-1977.

62. O'Hara EM, Harrison NM, Polomski BK, Barrett RA, Leen SB. The effect of inclusions on the high-temperature low-cycle fatigue performance of cast MarBN: Experimental characterisation and computational modelling. Fatigue Fract Eng Mater Struct. 2018;41(11):2288-2304.

63. Li DH, Li M, Shang DG, Gupta A, Sun W. Physically-based modeling of cyclic softening and damage behaviors for a martensitic turbine rotor material at elevated temperature. Int $J$ Fatigue. 2021;142:105956. 
64. Rae Y, Guo X, Benaarbia A, Neate N, Sun W. On the microstructural evolution in $12 \% \mathrm{Cr}$ turbine steel during low cycle fatigue at elevated temperature. Mater Sci Eng A. 2020;773: 138864.

65. Zhang B, Song ZM, Lei LM, Kang L, Zhang GP. Geometrical scale-sensitive fatigue properties of Ti-6.5Al-3.5Mo-1.5Zr-0.3Si alloys with a/ $\beta$ lamellar microstructures. J Mater Sci Technol. 2014;30(12):1287-1288.

66. Wan HY, Chen GF, Li CP, Qi XB, Zhang GP. Data-driven evaluation of fatigue performance of additive manufactured parts using miniature specimens. J Mater Sci Technol. 2019;35(6): 1137-1146.
How to cite this article: $\mathrm{Li} \mathrm{M}$, Maskill $\mathrm{S}$, Wen $\mathrm{Z}$, Yue Z, Sun W. A miniaturized thin-plate low cycle fatigue test method at elevated temperature. Fatigue Fract Eng Mater Struct. 2022;1-18. doi:10.1111/ffe.13665 